\title{
Typology of Online Tourist Information Search Strategies
}

\author{
Marinela Selmanaj ${ }^{1}$, Merita Murati ${ }^{2}$, \\ ${ }^{1}$ PHD Candidate, Regional Directorate of the Fund of Health Care Insurance Vlora, Albania, \\ marinelaselmanaj@gmail.com \\ ${ }^{2}$ PHD, Pavaresia University College/Chamber of Commerce and Industry of Vlora Region, \\ Albania,meri.murati@gmail.com
}

\begin{abstract}
The purpose of this study was to develop a typology of online tourist search strategies. Now that the Internet has become a widely accepted channel of travel information, understanding how consumers use its information sources has become imperative. As a channel of information, the Internet and its vast number of information sources present two key issues before determining a online tourist search typology. Therefore, to understand how consumers navigate these vast channels of information, one needs to develop profiles of their choose based around situational and behavioral characteristics. This can lead to a finer understanding of consumer needs, which in turn can help in developing more tailor-made solutions in terms of interface, design, and the actual products themselves. Using cluster analysis on a set of variables spanning 19 online travel information sources, the study identified three search clusters namely marginal, extensive, and moderate. It thereon used Chi/Square and Multinational Logistic regression to evaluate differences between the clusters. The study explained for both, the range of search as well as the combinations of search in the differentiation of clusters. Also, the study used traditional search contingencies or situational factors such as trip characteristics, and online contingencies such as Internet experience to differentiate clusters. Marketing and theoretical implications followed by future research suggestions were addressed.
\end{abstract}

Keywords: search strategies, online travel search behavior, cluster analysis, search contingencies 